\title{
Assessment of Intracranial Tumors Evaluated by Magnetic Resonance Imaging: A Retrospective Study
}

\author{
Shruti Kapoor ${ }^{1}$, V M Kulkarni² \\ ${ }^{1}$ PG Student, Department of Radio Diagnosis, 2Professor and Head, Department of Radio Diagnosis, Dr D Y Patil Medical \\ College, Hospital and Research Centre, Pimpri Pune, Maharashtra, India.
}

Corresponding author: Dr Shruti Kapoor, PG Student, Department of Radio Diagnosis, Dr D Y Patil Medical College, Hospital and Research Centre, Pimpri Pune, Maharashtra, India.

DOI: http://dx.doi.org/10.21276/ijcmsr.2018.3.4.6

How to cite this article: Shruti Kapoor, V M Kulkarni. Assessment of intracranial tumors evaluated by magnetic resonance imaging: a retrospective study. International Journal of Contemporary Medicine Surgery and Radiology. 2018;3(4):D21-D23.

\section{A B S T R A C T}

Introduction: Brain tumours are a diverse group of primary CNS tumours and secondary neoplasms arising either from the brain or from haematogenous spread from distant sites. Headache as a first and isolated presentation of brain tumours is much rarer. Hence; we planned the present study to retrospectively review 50 intracranial tumors evaluated by magnetic resonance imaging (MRI).

Material and methods: The present retrospective study included retrospective assessment of data records of the patients with intracranial tumour who underwent MRI evaluation. A total of 50 cases reviewed in the present study. Prevalence of each tumour in different genders was also done. All the results were compiled in Microsoft excel sheet and were analyzed by SPSS software.

Results: Invading Nasal tumour was found to be present in 5 cases, Pituitary tumour was found to be present in 7 cases, Meningioma was found to be present in 12 cases, Choroid plexus tumour was found to be present in 8 cases, Astrocytoma was found to be present in 6 cases and Oligodendroglioma was found to be present in 5 cases.

Conclusion: $\mathrm{MRI}$ is a useful tool in diagnosing the extension and morphology of brain tumour.

Key words: Brain, Intracranial, Tumour

\section{INTRODUCTION}

The neuroectoderm differentiates into the neuroepithelium, during embryogenesis, from which three primitive tissue are derived namely; the neuroblast, thespongioblast and the primitive ependymal cells. Intracranial neoplasms may arrive at any level of differentiation of these cells. ${ }^{1-3}$ Brain tumours are a diverse group of primary CNS tumours and secondary neoplasms arising either from the brain or from haematogenous spread from distant sites. Each tumour has a distinctivebiology, treatment and prognosis. ${ }^{4,5}$

The symptoms of primary brain tumours have only been described in secondary care series. These have been mainly retrospective studies with a potential for recall bias. Up to $70 \%$ of patients have a headache during the course of their illness, particularly in the final stages of their disease; however, this is broadly the same as the population incidence of headache. ${ }^{6,7}$ The incidence of headache at the time of diagnosis is between $23 \%$ and $56 \%$; however, all these figures vary with the clinical setting, and may have been affected by recall bias. Headache as a first and isolated presentation of brain tumours is much rarer: it is reported in $2-16 \%$ of patients. ${ }^{8,9}$

Hence; we planned the present study to retrospectively review 50 intracranial tumors evaluated by magnetic resonance imaging (MRI).

\section{MATERIAL AND METHODS}

The present retrospective study was conducted in the department of radio-diagnosis of the medical institute and it included retrospective assessment of data records of the patients with intracranial tumour who underwent MRI evaluation. Ethical approval was obtained from institutional ethical approval committee. Data records of all the patients were evaluated. For assessment of cranial tumors, a minimum of two different spin echo pulse sequences were performed. The first was a T2 weighted sequence with a long time of repetition (TR) between excitation pulses of 1.5 to 2 seconds, and multiple echo delay times (TE). The second was a TI weighted sequence consisting of a TR of 0.5 seconds and a TE of $28 \mathrm{msec}$. This couple of pulse sequences permitted us to find an empirical estimate of the $\mathrm{T} 1$ and $\mathrm{Tq}$ relaxation times of a tissue relative to normal brain and cerebrospinal fluid (CSF). Mathematical calculation of actual TI and Tp values within a lesion is also possible using these two pulse sequences.' Two experienced radiologists independently reviewed the cases. A total of 50 cases reviewed in the present study. Prevalence of each tumour in different genders was also done. 


\begin{tabular}{|l|l|c|}
\hline Parameter & Value \\
\hline Mean age (years) & 39.5 \\
\hline \multirow{2}{*}{ Gender } & Males & 28 \\
\cline { 2 - 3 } & Females & 22 \\
\hline \multicolumn{2}{|c|}{ Table-1: Demographic data } \\
\hline
\end{tabular}

\begin{tabular}{|l|c|c|}
\hline Tumour & $\begin{array}{c}\text { Number of } \\
\text { subjects }\end{array}$ & $\begin{array}{c}\text { Percentage of } \\
\text { subjects }\end{array}$ \\
\hline Invading Nasal tumour & 5 & 10 \\
\hline Pituitary tumour & 7 & 14 \\
\hline Meningioma & 12 & 24 \\
\hline Choroid plexus tumour & 8 & 16 \\
\hline Astrocytoma & 6 & 12 \\
\hline Oligodendroglioma & 5 & 10 \\
\hline Others & 7 & 14 \\
\hline Total Table-2: Distribution of intracranial tumour \\
\hline \multicolumn{2}{|c|}{} \\
\hline
\end{tabular}

\section{STATISTICAL ANALYSIS}

All the results were compiled in Microsoft excel sheet and were analyzed by SPSS software.

\section{RESULTS}

Data records of a total of 50 patients were included in the present study. Mean age of the subjects of the present study was 39.5 years. There were 28 males and 22 females (table-1). Invading Nasal tumour was found to be present in 5 cases, Pituitary tumour was found to be present in 7 cases, Meningioma was found to be present in 12 cases, Choroid plexus tumour was found to be present in 8 cases, Astrocytoma was found to be present in 6 cases and Oligodendroglioma was found to be present in 5 cases. Percentage distribution of the intracranial tumours in the present study was as follows: invading nasal tumours occurred in 10 percent of the subjects, pituitary tumour occurred in 14 percent of the subjects, meningioma occurred in 24 percent of the subjects, choroid plexus tumours occurred in 16 percent of the subjects, astrocytoma occurred in 12 percent of the subjects, astrocytoma occurred in 12 percent of the subjects and Oligodendroglioma occurred in 14 percent of the subjects (table-2).

\section{DISCUSSION}

In the present study, Data records of a total of 50 patients were included in the present study. Mean age of the subjects of the present study was 39.5 years. There were 28 males and 22 females. In a previous study, authors evaluated the axial origin, site, size, growth pattern, MRI signal intensity, evidence for edema, and paramagnetic contrast enhancement. Spectrum of intracranical tumours were studies which included intracranially invading nasal tumors, pituitary tumors, meningiomas, choroid plexus tumors, astrocytomas, ependymoma, and oligodendrogliomas. Axial derivation, location, size, and growth pattern were important diagnostic characteristics for tumor type. Signal intensity and contrast enhancement pattern allowed further differentiation. Characteristic MRI features that facilitate diagnosis and prognosis were identified. Precise diagnosis of tumor type grounded on these manifestations was not always feasible because of similarities in MRI appearance for some tumors. ${ }^{9}$ Invading Nasal tumour was found to be present in 5 cases, Pituitary tumour was found to be present in 7 cases, Meningioma was found to be present in 12 cases, Choroid plexus tumour was found to be present in 8 cases, Astrocytoma was found to be present in 6 cases and Oligodendroglioma was found to be present in 5 cases. Young BD et al assessed MR imaging manifestations of canine intracranial astrocytomas and oligodendrogliomas. In these cases, they also evaluated the differences in the MR features. Assessment of a total of 30 collective cases of astrocytoma and oligodendroglioma was done. Location of all the cases included in their study was cerebrum or thalamus. Association of most of the tumours of their study was seen with both gray and white matter. Hypointense on T1-weighted images and hyperintense on T2-weighted images were the signal features of both tumor types. Contrast enhancement, cystic areas within masses, ring like enhancement and hemorrhagic manifestations were the common findings for astrocytomas and oligodendrogliomas. In comparison to astrocytomas, Oligodendrogliomas were suggestively more predictive to contact the brain surface. Most common finding in the astrocytomas and oligodendrogliomas was the contact with the lateral ventricle. There was no significant MR features were found to be present that could significantly differentiate between the above mentioned tumour. Contrast enhancement was more common in high-grade tumors (III or IV) than low-grade tumors. ${ }^{10}$ In another study conducted by De Beuckeleer LH et al, authors assessed the sensitivity and specificity of these MR findings in diagnosis of cartilaginous tumors. Biopsy was done for confirming the diagnosis of individual lesions. Two different experienced radiologists were recruited for reviewing the cases and MR manifestations of all pathologies. From their study, the authors concluded that grading potentials of MR parameters are promising due to the high accuracy in diagnosing low-grade chondrosarcomas. ${ }^{11}$ Platt SR et al looked at the determinations got utilizing fine-needle aspiration (FNA) and biopsy of central cerebral masses with the histologic conclusions acquired by means of necropsy. All canines had clinical indications of cerebral illness and had a central cerebrum mass distinguished utilizing attractive reverberation imaging; all were in the long run euthanatized. Instantly after killing, the minds were expelled en coalition from the cranial hole. FNAs were gotten from each mass utilizing a 22-check hypodermic needle and a $12-\mathrm{mL}$ syringe. Cytologic arrangements were produced using each suction. A 14-check Tru-slice biopsy needle was utilized to acquire a center tissue test from each mass. The biopsy examples were settled in 10\% cradled formalin and submitted for histologic assessment. The minds were comparably settled and recolored. Six-micrometer-thick transverse areas of the mind were inspected infinitesimally. Neoplasia was affirmed in all pooches histologically in the 6-microm transverse areas. Four meningiomas, 2 astrocytomas, 2 oligodendrogliomas, 1 pituitary adenocarcinoma, and 1 neurofibrosarcoma were recognized. FNA effectively distinguished the majority of the majority as neoplastic. Cytologic conclusions corresponded 
with the histologic translation in 5 of the majority (half). Tru-cut biopsy examples distinguished each of the 10 masses as neoplastic; in 9 of the 10 (90\%), the determination associated with the histologic diagnosis. ${ }^{12}$ One restriction of using MRI as the primary study for assessment of cranial tumors was the statistic that small foci of calcification could not be visualized. Large plaques of intracerebral calcification could be identified as areas of absent signal, although occasionally even large areas of' calcification may be missed on the MK study. This presumably occurs when clense areas of calcification are actually interspersed within a matrix of abnormal tissue, and it is the latter component that emits the signal and is imaged on the MR study.

\section{CONCLUSION}

Under the light of above obtained results, the authors conclude that MRI is a useful tool in diagnosing the extension and morphology of brain tumour. However; further research is recommended.

\section{REFERENCES}

1. Shah SH, Soomro IN, Hussainy AS, Hassan SH. Clinico-pathological pattern of intracranial tumours in children. J Pak Med Assoc. 1999;49(3):63-5.

2. Smith D, Defalla B, Chadwick D. The misdiagnosis of epilepsy and the management of refractory epilepsy in a specialist clinic. QJM. 1999;92(1):15-23.

3. Mwangombe NJ, Ombachi RB. Brain tumours at the Kenyatta National hospital, Nairobi. East Afr Med J. 2006;77(8):444-7.

4. Boiardi A, Salmaggi A, Eoli M, et al. Headache in brain tumours: a symptom to reappraise critically. Neurol Sci. 2004;25(Suppl 3):S143-S147.

5. Morgan M, Jenkins L, Ridsdale L. Patient pressure for referral for headache: a qualitative study of GPs' referral behaviour. Br J Gen Pract. 2007;57(534):29-35.

6. Scheepers B, Clough P, Pickles C. The misdiagnosis of epilepsy: findings of a population study. Seizure. 1998;7(5):403-406.

7. Olasode BJ. A pathological review of intracranial tumours seen at the University College Hospital, Ibadan between 1980 and 1990. Niger Postgrad Med J. 2002;9(1):23-8.

8. Ohaegbulam SC, Saddeqi N, Ikerionwu S. Intracranial tumours in Enugu, Nigeria. Cancer. 1980;46(10):23322334

9. Kraft SL1, Gavin PR, DeHaan C, Moore M, Wendling LR, Leathers CW. Retrospective review of 50 canine intracranial tumors evaluated by magnetic resonance imaging. J Vet Intern Med. 1997;11(4):218-25.

10. Young BD, Levine JM, Porter BF, Chen-Allen AV, Rossmeisl JH, Platt SR, Kent M, Fosgate GT, Schatzberg SJ. Magnetic resonance imaging features of intracranial astrocytomas and oligodendrogliomas in dogs. Vet Radiol Ultrasound. 2011;52(2):132-41.

11. De Beuckeleer LH, De Schepper AM, Ramon F, Somville J. Magnetic resonance imaging of cartilaginous tumors: a retrospective study of 79 patients. Eur J Radiol. 1995;21(1):34-40.

12. Platt SR1, Alleman AR, Lanz OI, Chrisman CL. Comparison of fine-needle aspiration and surgical- tissue biopsy in the diagnosis of canine brain tumors. Vet Surg. 2002;31(1):65-9.

\section{Source of Support: Nil; Conflict of Interest: None}

Submitted: 26-09-2018; Accepted: 25-10-2018; Published online: 07-11-2018 